\title{
Identification and Characterization of Victorin Sensitivity in Arabidopsis thaliana
}

\author{
Jennifer M. Lorang, Nurgul Carkaci-Salli, and Thomas J. Wolpert \\ Department of Botany and Plant Pathology, Oregon State University, Corvallis, OR 97331-2902, U.S.A.
}

Submitted 1 December 2003. Accepted 23 December 2003.

\begin{abstract}
Cochliobolus victoriae is a necrotrophic fungus that produces a host-selective toxin called victorin. Victorin is considered to be host selective because it has been known to affect only certain allohexaploid oat cultivars containing the dominant $V b$ gene. Oat cultivars containing $V b$ are also the only genotypes susceptible to $C$. victoriae. Assays were developed to screen the "nonhost" plant of $C$. victoriae, Arabidopsis thaliana, for victorin sensitivity. Sensitivity to victorin was identified in six of 433 bulk populations of Arabidopsis. In crosses of Col-4 (victorin-insensitive) $\times$ victorin-sensitive Arabidopsis ecotypes, victorin sensitivity segregated as a single dominant locus, as it does in oats. This Arabidopsis locus was designated $L O V$, for locus orchestrating victorin effects. Allelism tests indicate that $L O V$ loci are allelic or closely linked in all six victorin-sensitive ecotypes identified. $L O V$ was localized to the north arm of Arabidopsis thaliana chromosome I. The victorin-sensitive Arabidopsis line LOV1 but not the victorin-insensitive line Col-4 was susceptible to $C$. victoriae infection. Consequently, the $L O V$ gene appears to be a genetically dominant, disease susceptibility gene.
\end{abstract}

Additional keywords: host-selective toxin.

We have been investigating a disease of oats, Victoria blight, caused by the fungus Cochliobolus victoriae (Meehan and Murphy 1946). C. victoriae is a necrotrophic fungus that produces a host-selective toxin called victorin. Purified victorin reproduces disease symptoms on Victoria blight-susceptible, oat genotypes (Meehan and Murphy 1947) and has been shown to induce programmed cell death (PCD) in sensitive oat tissue (Coffeen and Wolpert 2004; Curtis and Wolpert 2002, 2004; Navarre and Wolpert 1999; Yao et al. 2001, 2002). Victorin also induces physiological responses characteristic of plant host defense responses, such as callose deposition (Walton et al. 1982), the respiratory burst (Romanko 1959), lipid peroxidation (Navarre and Wolpert 1999), ethylene evolution (Shain and Wheeler 1975), extracellular alkalinazation (Ullrich and Novacky 1991), phytoalexin synthesis (Mayama et al. 1986), and K+ efflux (Wheeler and Black 1962).

Interestingly, in oats, victorin sensitivity and thus Victoria blight susceptibility are conditioned by a single dominant gene $(\mathrm{Vb})$ that is present in only a few oat genotypes. Furthermore, the $V b$ gene appears to be synonymous with a disease resistance gene $(P c-2)$ that confers resistance to specific races of

The contributions of the first two authors were equally significant.

Corresponding author: T. J. Wolpert; Center for Gene Research and Biotechnology; Telephone: +1.541.737.5293; Fax: +1.541.737.3573; E-mail: wolpertt@bcc.orst.edu the biotrophic fungus Puccinia coronata (Litzenberger 1949). That is, all oat genotypes that are sensitive to victorin are resistant to given races of $P$. coronata, and all oat genotypes that are insensitive to victorin are susceptible to those races of $P$. coronata. Despite extensive breeding efforts (Mayama et al. 1995; Welsh et al. 1954), mutation analysis (Luke et al. 1966), and generation of somatoclonal variants (Rines and Luke 1985), the two disease phenotypes, victorin sensitivity and $P$. coronata resistance, have not been genetically separable and, thus, could be conditioned by the same gene.

Given the relationship between $P$. coronata resistance and Victoria blight sensitivity, identifying $V b$ would not only increase our understanding of disease susceptibility and PCD in plants but could also increase our knowledge of plant disease resistance mechanisms. A problem in identifying $V b$ arises, however, because of the formidable size of the oat genome and the fact that $V b$ has, thus far, been found only in allohexaploid oats, for which detailed genetic maps are not available. Finding a genetically tractable system in which to study victorin sensitivity, therefore, is an appealing prospect.

In this study, we report the screening for and identification of victorin sensitivity in Arabidopsis thaliana and the finding that this victorin sensitivity, as in oats, confers susceptibility to C. victoriae. Furthermore, we genetically characterize and map the Arabidopsis victorin-sensitivity locus, thus setting the stage for a map-based approach toward cloning this disease susceptibility locus.

\section{RESULTS}

\section{Identification of victorin sensitivity} in Arabidopsis thaliana.

Accessions of Arabidopsis thaliana were screened for victorin sensitivity, in the hope of developing a genetically tractable system for the identification of one or more genes conferring this phenotype. Bulk ecotype collections of some 433 seed populations were screened, as these likely contain the greatest genetic diversity. A "negative" screen was conducted by growing seedlings for three weeks on agarose plugs and, then, placing the plugs in a solution of victorin. Each population was subsequently evaluated for any plant death within that population. This screen identified 26 populations that potentially contained individuals with sensitivity to victorin. Subsequently, individuals from these populations were grown to maturity and were screened by placing leaves into a solution of victorin and monitoring leaves for yellowing and death within a 48- to 96-h period (Fig. 1A). From this "positive" screen, toxin-sensitive individuals were identified in six different populations representing six different ecotypes (Table 1). The progeny of self-fertilizations of individuals from four out of six of these populations (ecotypes) were uniformly sensitive to vic- 
torin and thus appeared homozygous. Several individuals of ecotypes Rubezhnoe-2 and Tol-0 segregated for toxin sensitivity. To insure homozygosity for victorin sensitivity, each individual was self-fertilized for three generations and resulting progeny were screened for victorin sensitivity at each generation. The resulting S3 lines were designated as shown (Table 1).

\section{A single dominant gene confers victorin sensitivity in Arabidopsis.}

Initially, reciprocal crosses of the victorin-sensitive line, LOV1, were made into the toxin-resistant parent Col-4, and
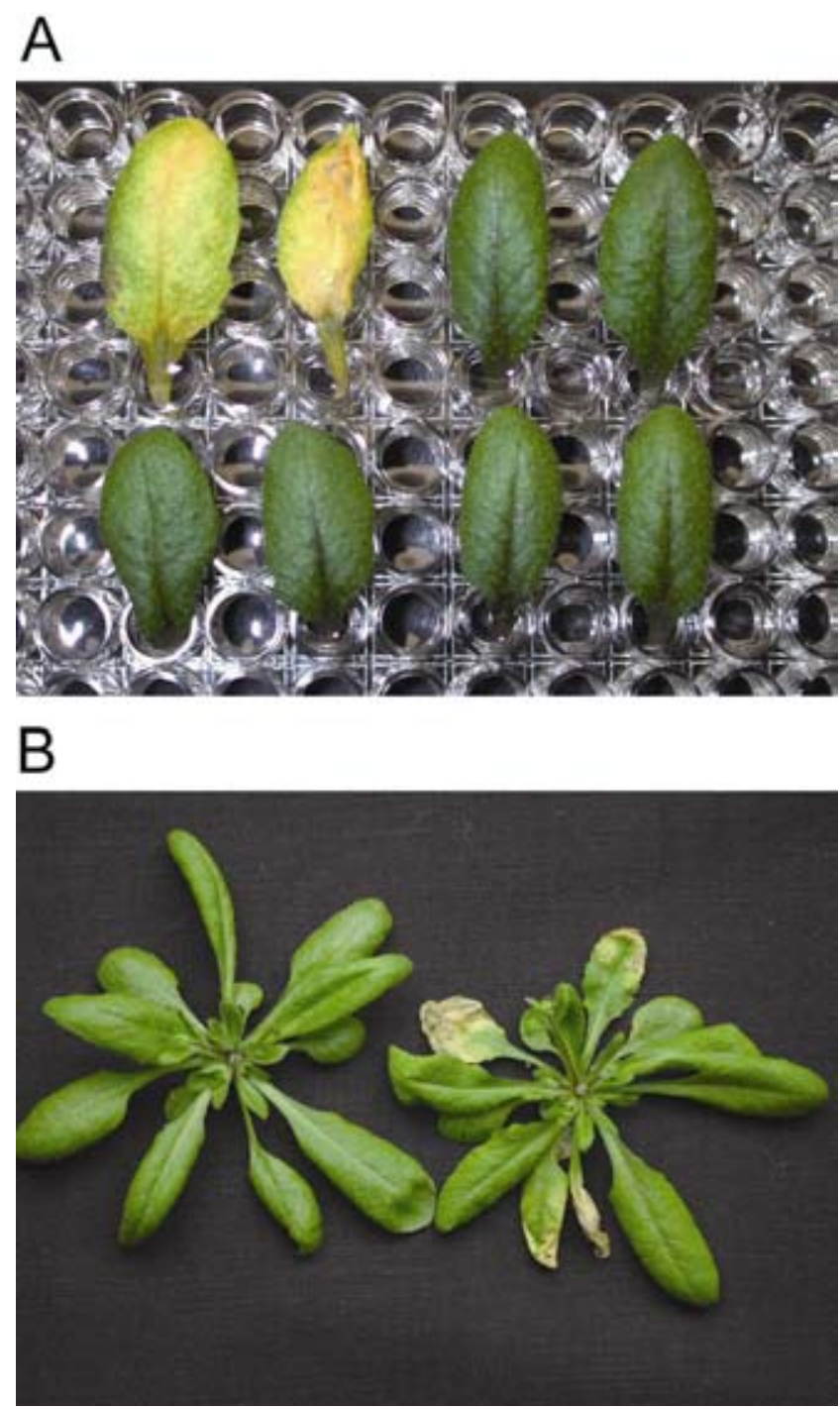

Fig. 1. Leaf assay for victorin-sensitive Arabidopsis. A, Leaves of Arabidopsis line LOV1 (left) and Col-4 (right), 4 days after treatment with $5 \mu \mathrm{g}$ of victorin C per ml (top) or water (bottom). B, Arabidopsis Col-4 (left) and LOV1 (right) 1 week after infiltration of four leaves on each plant with $10 \mu \mathrm{g}$ of victorin $\mathrm{C}$ per $\mathrm{ml}$. segregation analysis of victorin sensitivity was conducted (Table 2). Segregation was not affected by which parent was used as the maternal or paternal donor. A screen of 1,156 F2 progeny of the LOV $1 \times$ Col-4 resulted in a segregation ratio of 3:1 for victorin sensitivity, and thus, it appears that victorin sensitivity in Arabidopsis as is the case in oats is conferred by a single, dominant gene. We have tentatively named this gene $L O V$ (for locus orchestrating victorin effects). Subsequently, genetic analysis of victorin sensitivity in lines LOV2 through LOV6 were made, and victorin sensitivity in these lines also appears to be conferred by a single, dominant gene (Table 2 ).

A twofold approach was used to determine if the single dominant genes in each of the toxin-sensitive lines (LOV1 through LOV6) are allelic to one another. First, a standard genetic approach was pursued, in which one toxin-sensitive line was crossed with another toxin-sensitive line and F2 progeny were evaluated for toxin sensitivity. If loci conferring toxin sensitivity in given lines are unlinked, a 16:1 ratio of toxinsensitive to toxin-insensitive F2 progeny is expected. Crosses between lines in which toxin-sensitivity loci are allelic or tightly linked should yield no toxin-insensitive F2 progeny. Data showing LOV1 through LOV6 are either linked or allelic are presented in Table 3. It should be noted that, because the physical characteristics and growth rates among the toxin-sensitive ecotypes vary greatly, F2 progeny that are segregating for these diverse characters were sometimes difficult to cross and score for toxin sensitivity (Table 3, LOV6 $\times$ LOV4), in part, because toxin sensitivity closely resembles senescence. It

Table 2. F2 segregation analysis of victorin sensitivity in six victorinsensitive Arabidopsis lines ${ }^{\mathrm{a}}$

\begin{tabular}{lcccc}
\hline $\begin{array}{l}\text { Cross } \\
\text { Male } \times \text { Female }\end{array}$ & $\begin{array}{c}\text { F1 } \\
\text { phenotype }\end{array}$ & $\begin{array}{c}\text { F2 segregation } \\
\text { S(\%):I(\%) }\end{array}$ & Total & $\begin{array}{c}\mathbf{3 : 1} \\
\boldsymbol{P}>\mathbf{0 . 0 5}\end{array}$ \\
\hline Col-4 parent & $\mathrm{I}$ & - & - & - \\
Col-4 $\times$ LOV1 & $\mathrm{S}$ & $127(77): 38(23)$ & 165 & $*$ \\
LOV1 $\times$ Col-4 & $\mathrm{S}$ & $876(76): 280(24)$ & 1,156 & $*$ \\
LOV2 $\times$ Col-4 & $\mathrm{S}$ & $75(74): 26(26)$ & 101 & $*$ \\
LOV3 $\times$ Col-4 & $\mathrm{S}$ & $95(72): 38(28)$ & 133 & $*$ \\
LOV4 $\times$ Col-4 & $\mathrm{S}$ & $71(74): 25(26)$ & 96 & $*$ \\
LOV5 $\times$ Col-4 & $\mathrm{S}$ & $95(75): 31(25)$ & 126 & $*$ \\
LOV6 $\times$ Col-4 & $\mathrm{S}$ & $101(74): 35(26)$ & 136 & $*$ \\
\hline
\end{tabular}

${ }^{\mathrm{a}} \mathrm{I}=$ victorin insensitive, $\mathrm{S}=$ victorin sensitive.

Table 3. Allelism of victorin sensitivity loci in six victorin-sensitive Arabidopsis lines.

\begin{tabular}{lccc}
\hline Cross & $\begin{array}{c}\text { F2 segregation } \\
\text { S:I }\end{array}$ & Total & $\begin{array}{c}\text { Mapped to } \\
\text { chromosome 1 }\end{array}$ \\
\hline LOV2 $\times$ LOV1 & $128: 0$ & 128 & $*$ \\
LOV3 $\times$ LOV1 & $143: 0$ & 143 & $*$ \\
LOV4 $\times$ LOV1 & $100: 0$ & 100 & $*$ \\
LOV5 $\times$ LOV4 & $195: 0$ & 195 & $*$ \\
LOV6 $\times$ LOV4 & $138: 5 ?^{c}$ & 143 & $*$ \\
\hline
\end{tabular}

${ }^{a} \mathrm{I}=$ victorin insensitive, $\mathrm{S}=$ victorin sensitive.

b Mapped to a 10- to 15-cM region of chromosome 1.

${ }^{\mathrm{c}}$ Difficult to score individuals.

Table 1. Arabidopsis ecotypes having victorin-sensitive individuals

\begin{tabular}{lclccc}
\hline Ecotype & Stock number & Geographical origin & $\begin{array}{c}\text { Number of victorin- } \\
\text { sensitive individuals }\end{array}$ & $\begin{array}{c}\text { Segregation for sensitivity } \\
\text { in any S1 plant }\end{array}$ & S3 line designation \\
\hline Cl-0 & CS1082 & Germany & $14 / 15$ & No & NOV1 \\
Sp-0 & CS1530 & Germany & $4 / 15$ & No & LOV2 \\
C24 & CS906 & Netherlands & $25 / 25$ & Yes & LOV3 \\
Rubezhnoe-2 & CS928 & Ukraine & $14 / 15$ & No & LOV4 \\
Sha & CS929 & Tadjikistan & $20 / 22$ & Yes & LOV6 \\
Tol-O & CS8020 & U.S.A. & $12 / 15$ & & \\
\hline
\end{tabular}


is also possible that suppression of victorin sensitivity occurs at a low frequency in LOV6 $\times$ LOV 4 F2 progeny. To resolve the allelism question, we pursued a second approach based on polymerase chain reaction (PCR) markers.

We pursued a PCR-based mapping approach to determine if the single dominant genes in toxin-sensitive lines LOV1 through LOV6 are allelic. We initiated PCR-based mapping of LOVI, employing a set of markers (primarily, simple size length polymorphism markers [SSLPs]) (Tautz 1989) that span the five chromosomes of Arabidopsis. Among these, we identified markers that are polymorphic between Col-4 and the victorin-sensitive parent, LOV1. Linkage analysis based on 160 chromosomes of victorin-resistant progeny clearly indicated that the LOVI locus is located on the north arm of chromosome 1 , approximately 11 centimorgans (cM) centromeric of marker nga59 and $14 \mathrm{cM}$ telomeric of marker nga392 or a rough map location at approximately the 10 to $20 \mathrm{cM}$ region of chromosome 1 (Fig. 2). Other PCR markers in this region, nga63 or F22G5, T12C24, and F20D23 were then used to analyze linkage of victorin sensitivity in lines LOV1 through LOV6. Nga59, nga63, and nga392 are established PCR markers. We created markers F22G5, T12C24, and F20D23 by designing primers bordering simple-sequence repeats identified in this region of the Arabidopsis genome. PCR markers that were polymorphic between respective parents of each cross were first identified, and linkage analysis was then conducted. Based on data from at least 96 plants and a minimum of 24 toxin-insensitive chromosomes per line, the locus conferring victorin sensitivity in all six LOV lines and consequently in the six different Arabidopsis ecotypes mapped to within $4 \mathrm{cM}$

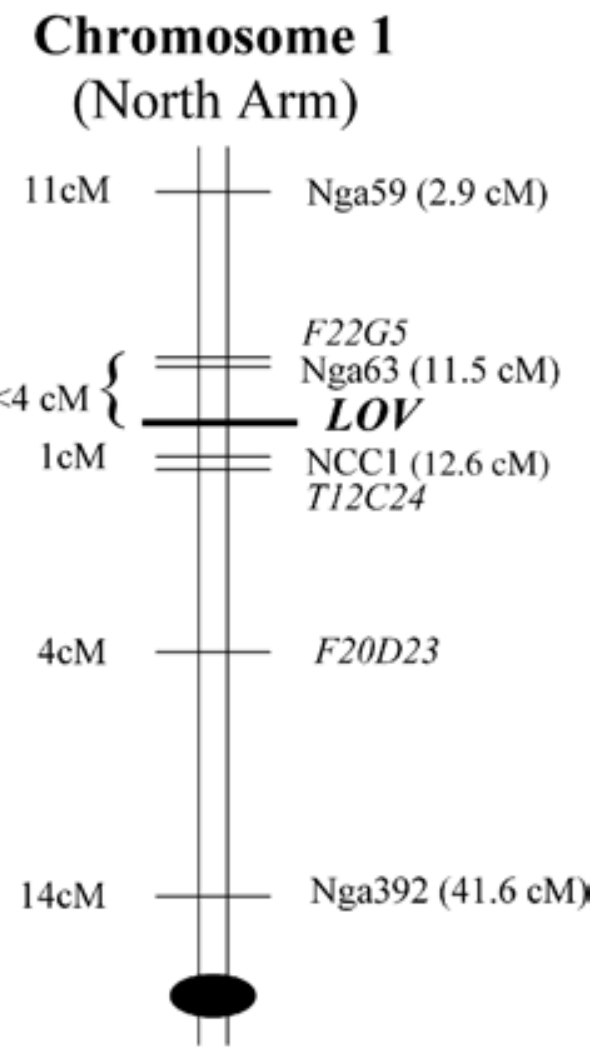

Fig. 2. Genetic mapping of $L O V$. Map positions of established markers are in parentheses (right). Markers not previously described are shown in italics. The genetic distance between the LOV locus and markers in LOV $1 \times$ Col-4 are shown on the left. The distance between nga63 or F22G5 and $L O V$ is shown as $<4 \mathrm{cM}$, because it represents the distance for all crosses of lines LOV1 through LOV $6 \times$ Col-4 and the genetic distance was not identical for all crosses. The centromere is shown as a black circle.
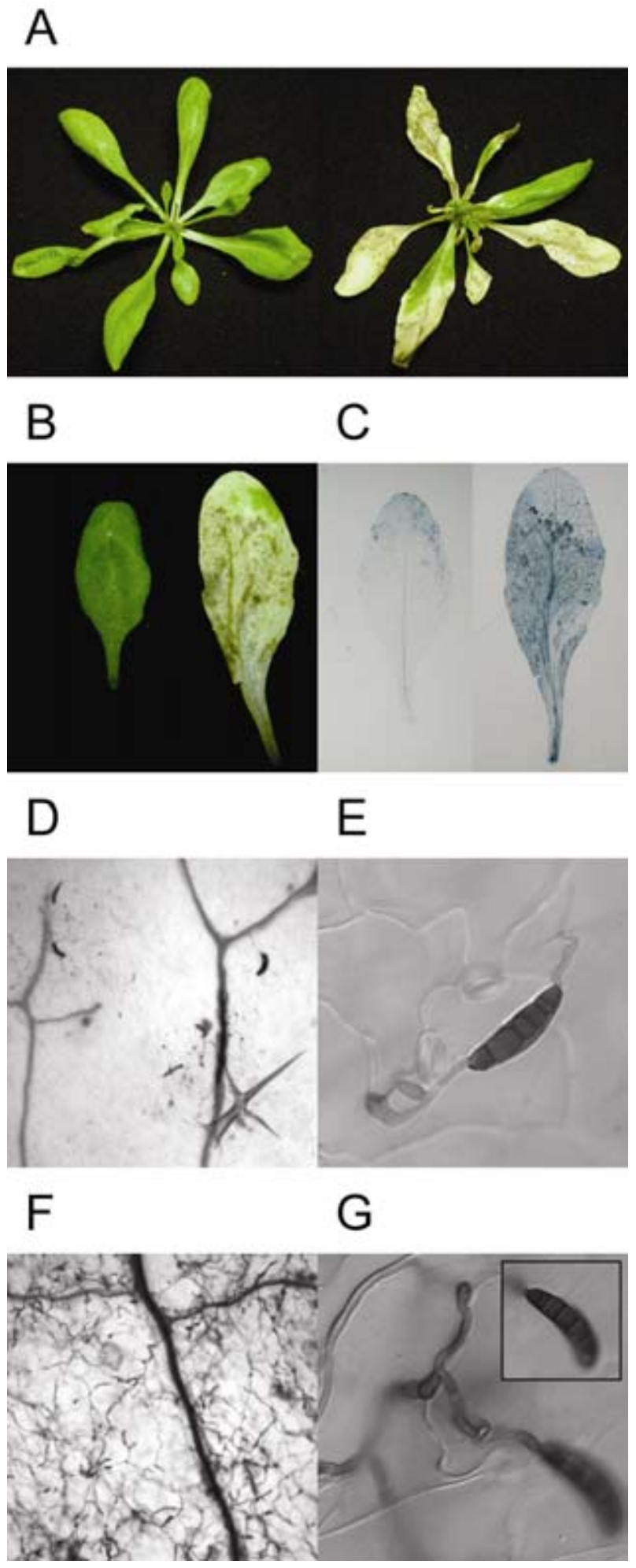

Fig. 3. Arabidopsis lines Col-4 and LOV1 after inoculation with Cochliobolus victoriae. A, Whole plants of Col-4 (left) and LOV1 (right) 7 days after inoculation with $C$. victoriae. B, Close-up view of an individual leaf excised from a Col-4 (left) or LOV1 (right) plant, 7 days after inoculation with $C$. victoriae. $\mathbf{C}$, Leaves in B, Col-4 (left) and LOV1 (right), stained with trypan blue and cleared. D through $\mathbf{G}$, Nomarski microscopy of leaves in $\mathrm{C}$ : $\mathrm{D}=\mathrm{Col}-4$ at $4 \times, \mathrm{E}=\mathrm{Col}-4$ at $40 \times, \mathrm{F}=\mathrm{LOV} 1$ at $4 \times$, and $\mathrm{G}=\mathrm{LOV} 1$ at $40 \times$. Insert. Upper focal plane showing a conidia spore (out of focus in $\mathrm{E}$ ) in focus, on the leaf surface. 
of either marker F22G5, nga63, or both, on the North arm of chromosome 1 . Thus, the loci conferring victorin sensitivity in the six different Arabidopsis ecotypes are most likely allelic or at least tightly linked. We have designated these loci LOVI through LOV6.

\section{Victoriae blight of Arabidopsis.}

Pathogenicity assays of the victorin-sensitive line LOV1 inoculated with $C$. victoriae were conducted, to evaluate the possibility that victorin sensitivity confers susceptibility to $C$. victoriae in Arabidopsis. The victorin-insensitive line Col-4 was also evaluated for comparison. Three- to four-week-old plants of each line, LOV1 and Col-4, were sprayed to saturation with a suspension of $C$. victoriae conidia. Conidia had been washed to remove excess victorin. Plants were evaluated 5 to 7 days later for disease symptoms. No Col-4 plant showed any symptoms; however, all of the LOV-1 plants showed symptoms of chlorosis and necrosis on some leaves (Fig. 3A and B). Susceptibility of leaves was influenced by leaf age, with older leaves appearing more susceptible than younger leaves. Infection also required high humidity. Examination of stained, fixed tissue revealed that hyphae were abundant in some but not all chlorotic tissue and in necrotic tissue of LOV1 leaves (Fig. 3B and C, right side). No hyphae were visible in Col-4 leaves (Fig. 3B and C, left side, and D). Microscopic examination revealed that conidia germinated and formed appressoria on Col-4 leaves, but little or no penetration of the fungus was visible (Fig. 3E). In contrast, on LOV1 leaves, C. victoriae hyphae penetrated tissue (Fig. 3G) and proliferated in the intercellular spaces of the mesophyll (Fig. $3 F)$. In completion of Koch's postulates, infected tissue was surface-sterilized and plated on water agar, and $C$. victoriae sporulation from tissue of victorin-susceptible Arabidopsis was observed.

\section{DISCUSSION}

Toward the goal of finding a genetically tractable system in which to investigate the molecular nature of victorin-induced plant cell death and disease susceptibility, assays were developed for evaluating victorin sensitivity in Arabidopsis thaliana. Initial evaluations were conducted with a negative assay, in that plants that appeared to be sensitive to victorin were killed and thus could not be recovered. Consequently, this assay was limited to the identification of populations rather than specific individuals that potentially contained victorin sensitivity. However, with this assay, thousands of seedlings could be evaluated in a relatively small area and with an obtainable amount of toxin. Thus, the high-risk experimental approach of searching for sensitivity to a "host-selective" toxin in a large population of "nonhost" plants was feasible with the seedling assay. Subsequently, leaf assays were developed as positive assays, so that seeds could be recovered from individual plants that had been evaluated. These assays required more labor and considerably fewer plants could be evaluated; however, plants of interest could be retained and progeny could be developed for further study.

A total of 433 populations were evaluated for victorin sensitivity, and victorin-sensitive individuals were selected from six of these populations. Given these numbers, it would seem that victorin sensitivity is relatively rare in Arabidopsis. However, the possibility that victorin-sensitive individuals also occur within the 427 populations from which victorin-sensitive individuals were not selected cannot be ruled out. The nature of the negative assay, which was designed to screen large numbers of small seedlings with minimal quantities of toxin, lends itself to some occurrence of plant death even in Col-4 control plants or in untreated water controls. Furthermore, toxin sensitivity can resemble plant senescence. For these reasons, it is likely that only six of the 26 populations selected as potentially having victorin sensitivity clearly included individuals that were convincingly victorin-sensitive. Choosing individuals for further study necessitated rigorous selection, because scoring of individuals for genetic analysis, particularly for map-based cloning, requires an unequivocal phenotype.

A genetic analysis of victorin sensitivity in Arabidopsis thaliana revealed a 3:1 segregation ratio of victorin-sensitive to victorin-insensitive F2 plants; thus, a single dominant gene appears to condition victorin sensitivity in Arabidopsis thaliana, as it does in Avena sativa. We have designated this gene $L O V$, for locus orchestrating victorin effects. As a first step in an investigation of the genetic diversity of the $L O V$ loci in the six victorin-sensitive Arabidopsis ecotypes, we determined whether these loci are allelic (or linked) or distinct. A combination of genetic allelism tests and PCR-based mapping of the $L O V$ loci revealed that all six $L O V$ loci are allelic or at least tightly linked and occur near the 12-cM region of chromosome 1.

The occurrence of victorin sensitivity in taxa as distantly related as Avena sativa and Arabidopsis is curious. Identifying any victorin-sensitive Arabidopsis was fortunate and somewhat surprising, given that victorin is a host-selective toxin and no plant other than a few oat cultivars has been known to be a host of $C$. victoriae. Traditionally, host-selective toxins were by definition thought to have extremely limited sensitivity ranges. More recently, however, Brandwagt and associates (2001) found AAL toxin affects several Nicotiana spp., most of which are nonhosts of Alternaria alternata f. sp. lycopersici, the fungus that produces AAL toxin. AAL toxin is also toxic to monkey kidney cells (Wang et al. 1996). Clearly then, AAL toxin cannot be considered host selective. In maize, mutations of the $\mathrm{Hml}$ and $\mathrm{Hm} 2$ loci, which arose in inbred lines, confer sensitivity to HC-toxin (Johal and Briggs 1992; Meeley et al. 1992; Multani et al. 1998). Hml and $\mathrm{Hm} 2$ both encode a carbonyl reductase, HC-toxin reductase (HCTR) (Johal and Briggs 1992). HCTRs are present in all grass species, so under the appropriate selection pressure or through directed mutation of the orthologous loci, other grasses conceivably could also become sensitive to HC-toxin. Whether these grasses would also become hosts to Cochliobolus carbonum, the fungus that produces HC-toxin, is unknown but would establish whether HC-toxin is truly host selective. In this study, we demonstrated that victorin-sensitive Arabidopsis are apparently a host of $C$. victoriae and victorin-insensitive Arabidopsis can be resistant to $C$. victoriae. Thus victorin, in this circumstance, is by definition truly host-selective. Consequently, the Arabidopsis LOV gene, as in the case of the oat $V b$ gene, appears to be a true disease-susceptibility gene and presumably functions as such by conditioning toxin sensitivity.

The seed populations from which victorin sensitivity was identified were collected from diverse geographical regions: the Ukraine, Germany, The Netherlands, Tadjikistan, and the U.S.A. Currently, we have no idea of what, if any, selection pressure led to the victorin recognition event and, consequently, if any of these regions share a common selective pressure. In oats, victorin sensitivity has been observed only in lines from Uruguay, which were introduced to confer rust resistance (Litzenberger 1949). The purposeful selection of the $P c$-2 gene most likely provided a selection pressure for $V b$. In Arabidopsis, toxin-sensitive individuals are derived from widely dispersed, distinct populations and ecotypes. As these individuals exhibit morphological variability and differences in growth rate and flowering time, it is also possible that they harbor genetic variability at the $L O V$ locus. Such variability could provide a valuable genetic resource for studies directed at 
understanding the molecular basis of the specificity of victorininduced plant cell death.

The apparent allelism of all six Arabidopsis LOV loci as well as the single dominant-gene nature of victorin-induced cell death in both oats and Arabidopsis and the fact that $L O V$ as well as $V b$ confers susceptibility to $C$. victoriae implies that some commonality with regard to victorin recognition exists between oats and Arabidopsis. It is likely that the LOV gene is either functionally similar to the $V b$ gene or both encode components within a similar signaling pathway. Because the gene conferring victorin sensitivity in oats is thought to be synonymous with a rust resistance gene, it is possible that victorin interacts with a resistance gene product. Physiological studies of victorin support this possibility because victorin appears to induce many of the plant responses classically associated with elicitors (Wolpert et al. 2002). Consequently, it is possible that the $L O V$ gene from Arabidopsis encodes a resistance-like protein that coincidently functions in the recognition of victorin as a race-specific elicitor or that the $L O V$ gene encodes a component of a resistance-signaling pathway. Thirteen receptor-like kinases and three other defense-signaling gene candidates reside in the region to which the $L O V$ gene maps. Certainly, however, other possibilities could be imagined as well, including the existence of a distinct response pathway for disease susceptibility. Irrespective of the specific nature of the $L O V$ locus, identification of victorin sensitivity in Arabidopsis, a plant for which a vast array of genetic resources have been developed, will greatly facilitate our investigation of victorin's mode of action and will make possible the identification of the $L O V$ and possibly the $V b$ gene. A mapbased cloning effort to identify the $L O V$ gene is now possible and is currently underway.

\section{MATERIALS AND METHODS}

\section{Plant material and growth conditions.}

Seeds of Arabidopsis thaliana ecotypes were obtained from The Ohio State University Arabidopsis Biological Resource Center. Bulk-collected populations were selected based on the assumption that these populations would contain the greatest genetic diversity. A total of 433 populations were examined for victorin sensitivity. The names, numerical designators, and geographical origins for all of these populations are available upon request.

Seeds were surface-sterilized in $0.5 \%$ sodium hypochloride for 3-min, were rinsed three times with sterile distilled water, were dried on sterile filter paper, and were stored at $4^{\circ} \mathrm{C}$. With the exception of seed used for the seedling assay described below, sterile seed was incubated at $4^{\circ} \mathrm{C}$ in a $0.1 \%$ agar solution for 5 days, and then, was applied to soil and grown at $22^{\circ} \mathrm{C}$ under a long-day photoperiod (16 h of light, $8 \mathrm{~h}$ of dark).

\section{Victorin sensitivity assays.}

Victorin sensitivity assays were conducted with victorin C that was purified as previously described (Macko et al. 1985; Wolpert et al. 1985). For seedling assays, 13-mm disks were cut with a cork borer into $1.5 \%$ (wt/vol) agar (Bacto agar) in minimal salts nutrient solution in 86-mm petri dishes, and 20 seeds from a single population were placed on each agar disk. The petri dishes were sealed with parafilm and incubated for five days at $4^{\circ} \mathrm{C}$. Following this stratification period, petri dishes were placed under fluorescent lights at room temperature under a long-day photoperiod of $16 \mathrm{~h}$ of light and $8 \mathrm{~h}$ of dark. After growth for three weeks, the agar disks containing the seedlings were transferred to $8 \times 10$-inch glass baking dishes and were placed on top of a "diamond mesh" plastic screen containing holes measuring approximately $7 \times 9 \mathrm{~mm}$. Each plastic screen was elevated above the bottom of the bak- ing dish by placing it over 1-cm-diameter glass rods, and the dish contained nutrient solution up to the level of the plastic screening, such that the roots from the plants growing on the agar disks were immersed in nutrient solution. Following transfer, the baking dishes were covered with plastic wrap. The following day, the plastic wrap was folded back from the corners of the dish. Over the course of the next two days, the plastic wrap was gradually folded back so that, by the end of the third day, the dish was completely uncovered. Following this "hardening off" period, the nutrient solution was removed and replaced with a solution of purified victorin $\mathrm{C}(5 \mu \mathrm{g} / \mathrm{ml})$. After two days, additional victorin solution was added to the original level, and plants were monitored for death for one week.

For the positive screen, individual leaf assay, individual plants were tested for victorin sensitivity by gently removing leaves from the rosettes of 3-week-old plants. Leaves were placed into individual wells of 96-well, 0.2-ml, thin-walled thermal cycler plates (Out Patient Services Inc., Petaluma, CA, U.S.A.). One leaf from each plant was placed in a well containing $300 \mu \mathrm{l}$ of distilled water, and two leaves from the same plant were each placed in separate wells containing $300 \mu \mathrm{l}$ of $5 \mu \mathrm{g} / \mathrm{ml}$ victorin $\mathrm{C}$. Leaves were then monitored for symptom development over a $96-\mathrm{h}$ period. For genetic analysis, in which large numbers of plants needed to be scored, the positivescreen leaf assay was modified to a less labor-intensive, whole-plant leaf assay. For the whole-plant leaf assay, the first true leaves of 16- to 18-day-old plants were infiltrated with 10 $\mu \mathrm{g}$ of victorin per $\mathrm{ml}$, using a $1-\mathrm{ml}$ syringe barrel containing no needle. Infiltrations were repeated, if necessary, on successive leaves every two to three days for up to 10 days or until plants could be conclusively scored for their victorin response.

\section{DNA preparation, PCR, and genetic analyses.}

DNA was purified from leaf tissue according to Edwards and associates (1991), and PCR was performed (Ausubel et al.1997). Primers dispersed throughout the five chromosomes of Arabidopsis (ResGen, Invitrogen Corp., Carlsbad, CA, U.S.A.) were selected from sequence information available at The Arabidopsis Information Resource.

Victorin-sensitive plants were allowed to self-fertilize, and progeny were tested for toxin sensitivity with the leaf assays described above. Toxin-sensitive individuals were selected in each generation for self-fertilization. Sensitive progeny were self-fertilized for three successive generations to create $S_{3}$ lines. For segregation analysis, pollen of each $S_{3}$ line was used to fertilize Col-4 immature flowers or, for allelism tests, immature flowers of the designated $\mathrm{S}_{3}$ lines. Reciprocal crosses were also made to assess for cytoplasmic inheritance in Col-4 $\times S_{3}$. F1 seeds were planted, and the plants self-fertilized to make F2 seed. In scoring of toxin-resistant F2 individuals for mapping analysis, phenotypes were confirmed by progeny testing in the F3 generation.

\section{Pathogenicity tests, detection of $C$. victoriae in planta.}

C. victoriae was cultured on V8 media plates at $25^{\circ} \mathrm{C}$ under continuous light. Spores of one-week-old cultures were harvested by scraping plates in $0.01 \%$ Tween 20 , were washed two times with $25 \mathrm{ml}$ of $0.01 \%$ Tween 20 , and were resuspended to a concentration of $10^{6}$ spores per ml. C. victoriae spores were sprayed onto 3- to 4-week-old plants with an aspirator until runoff. Plants were then incubated at $100 \%$ humidity in the growth chamber at $22^{\circ} \mathrm{C}$ under a long-day photoperiod ( $16 \mathrm{~h}$ of light, $8 \mathrm{~h}$ of dark), until symptoms appeared. For visualization of fungi, leaves were excised, boiled for $3 \mathrm{~min}$ in an acidic solution of trypan blue ( $0.03 \%$ trypan blue dissolved in distilled water, glycerol, and lactic acid in 1:1:1 ratio.), and then, were left to incubate overnight, according to a method 
modified from Keogh and associates (1980). Leaves were cleared with hydrochlorate ( $2.5 \mathrm{~g}$ per $\mathrm{ml}$ of water) for $24 \mathrm{~h}$ and were mounted on microscope slides in hydrochlorate and glycerol (1:1). Specimens were visualized with Nomarski optics.

\section{ACKNOWLEDGMENTS}

We would like to thank The Ohio State University Arabidopsis Biological Resource Center for seed. We are also grateful to M. Curtis for assistance with microscopy and to D. Ptacek and S. Yoon for technical assistance. This work was supported in part by grants from the United States Department of Agriculture, National Research Initiative Competitive Grants Program (2001-35319-10896) and the National Science Foundation (IBN-9631442).

\section{LITERATURE CITED}

Ausubel, F. M., Brent, R., Kingsron, R. E., Moore, D. D., Seidman, J. F., Smith, J. A., and Struhl, K. 1997. Current Protocols in Molecular Biology. John Wiley and Sons, New York.

Brandwagt, B. F., Kneppers T. J. A., Van Der Weeden G. M., Nijkamp H. J. J., and Hille, J. 2001. Most AAL toxin-sensitive Nicotiana species are resistant to the tomato fungal pathogen Alternaria alternata f. sp. lycopersici. Mol. Plant-Microbe Interact. 14:460-470.

Coffeen, W. C., and Wolpert, T. J. Purification and characterization of serine proteases that exhibit caspase-like activity and are associated with programmed cell death in Avena sativa. Plant Cell, in press.

Curtis, M. J., and Wolpert, T. J. 2002. The oat mitochondrial permeability transition and its implication in victorin binding and induced cell death. Plant J. 29:295-312.

Curtis, M. J., and Wolpert, T. J. The victorin-induced mitochondrial permeability transition precedes cell shrinkage and biochemical markers of cell death, and shrinkage occurs without loss of membrane integrity. Plant J., in press.

Edwards, K., Johnstone, C., and Thompson C. 1991. A simple and rapid method for the preparation of plant genomic DNA for PCR analysis. Nucleic Acids Res. 19:1349.

Johal, G. S, and Briggs, S. P. 1992. Reductase activity encoded by the HM1 disease resistance gene in maize. Science 258:985-987.

Keogh, R. C., Deverall, F. J., and McLeod, S. 1980. Comparison of histological and physiological responses to Phakopsora pachyrhizi in resistant and susceptible soybean. Trans. Br. Mycol. Soc. 74:329-333.

Litzenberger, C. S. 1949. Nature of susceptibility to Helminthosporium victoriae and resistance to Puccinia coronata in Victoria oats. Phytopathology 39:300-319.

Luke, H. H., Murphy, H. C. and Peter, F. C. 1966. Inheritance of spontaneous mutations of the victoria locus in oats. Phytopathology 56:210-212.

Macko, V., Wolpert, T. J., Acklin, W., Jaun, B., Seibl, J., Meili, J., and Arigoni, D. 1985. Characterization of victorin $\mathrm{C}$, the major host-selective toxin from Cochliobolus victoriae: Structure of degradation products. Experientia 41:1366-1370.

Mayama, S., Tani, T., Ueno, T., Midland, S. L., Sims, J. J., and Keen, N. T. 1986. The purification of victorin and its phytoalexin elicitor activity in oat leaves. Phys. Mol. Plant Pathol. 29:1-18.
Mayama, S., Bordin, A. P. A., Morikawa, T., Tanpo, H., and Kato, H. 1995. Association of avaenalumin accumulation with co-segregation of victorin sensitivity and crown rust resistance in oat lines carrying the $P c-2$ gene. Physiol. Mol. Plant Pathol. 46:263-274.

Meehan, F., and Murphy, H. C. 1946. A new Helminthosporium blight of oats. Science 104:413-414

Meehan, F., and Murphy, H. C. 1947. Differential phytotoxicity of metabolic by-products of Helminthosporium victoriae. Science 106:270271.

Meeley, R. B., Johal G. S., Briggs S. P., and Walton, J. 1992. A biochemical phenotype of a disease resistance gene in maize. Plant Cell 4:71-77.

Multani D. S., Meeley, R. B., Paterson A. H., Gray, J., and Briggs, S. P. 1998. Plant-pathogen microevolution: Molecular basis for the origin of a fungal disease in maize. Proc. Acad. Natl. Sci. U.S.A. 95:1686-1691.

Navarre, D. A., and Wolpert, T. J. 1999. Victorin induction of an apoptotic, senescence-like response in oats. Plant Cell 11:237-249.

Rines, H. W., and Luke, H. H. 1985. Selection and regeneration of toxininsensitive plants from tissue cultures of oats (Avena sativa) susceptible to Helminthosporium victoriae. Theor. Appl. Genet. 71:16-21.

Romanko, R. R. 1959. A physiological basis for resistance of oats to victoria blight. Phytopathology 49:32-36.

Shain, L., and Wheeler, H. 1975. Production of ethylene by oats resistant and susceptible to victorin. Phytopathology 65:88-89.

Tautz, D. 1989. Hypervariability of simple sequences as a general source of polymorphic DNA markers. Nucleic Acids Res. 17:6463-6471.

Ullrich, C. I., and Novacky, A. J. 1991. Electrical membrane properties of leaves, roots and single root cap cells of susceptible Avena sativa. Plant Physiol. 95:675-681.

Walton, J. D., and Earle, E. D. 1985. Stimulation of extracellular polysaccharide synthesis in oat protoplasts by the host-specific phytotoxin victorin. Planta 165:407-415.

Wang H., Jones, C., Ciacci-Zanella, J., Holat, T., and Gilchrist, D. G. 1996. Proc. Natl. Acad. Sci. U.S.A. 93:3461-3465.

Welsh J. N, Perurson, B., and Machacek J. E. 1954. Associate inheritance of reaction to races of crown rust, Puccinia coronata avenae Erikss. and to Victoria blight, Helminthosporium victoriae M. and M., in oats. Can. J. Bot. 32:55-68.

Wheeler, H., and Black, H. S. 1962. Change in permeability induced by victorin. Science 137:983-984.

Wolpert T. J., Dunkle L. D., and Ciuffetti, L. M. 2002. Host-selective toxins and avirulence determinants: What's in a name? Annu. Rev. Phytopathol. 40:251-285.

Wolpert, T. J., Macko, V., Acklin, W., Jaun, B., Seibl, J., Meili, J., and Arigoni, D. 1985. Structure of victorin C, the major host-selective toxin from Cochliobolus victoriae. Experientia 41:1524-1529.

Yao, N., Tada, Y., Park, P., Nakayashiki, H., Tosa, Y., and Mayama, S. 2001. Novel evidence for apoptotic cell response and differential signal in chromatin condensation and DNA cleavage in victorin-treated oats. Plant $\mathrm{J}$ 28:13-27.

Yao, N., Tada, Y., Sakamoto, M., Nakayashiki, H., Park, P., Tosa, Y., and Mayama, S. 2002. Mitochondrial oxidative burst involved in apoptotic response in oats. Plant J. 30:567-579.

\section{AUTHOR-RECOMMENDED INTERNET RESOURCE}

The Arabidopsis Information Resource: www.arabidopsis.org/home.html 